\title{
Joshua Edel and Andrew J. deMello (Eds.): Nanofluidics. Nanoscience and nanotechnology
}

\author{
Jan Eijkel
}

Published online: 14 August 2009

C The Author(s) 2009. This article is published with open access at Springerlink.com

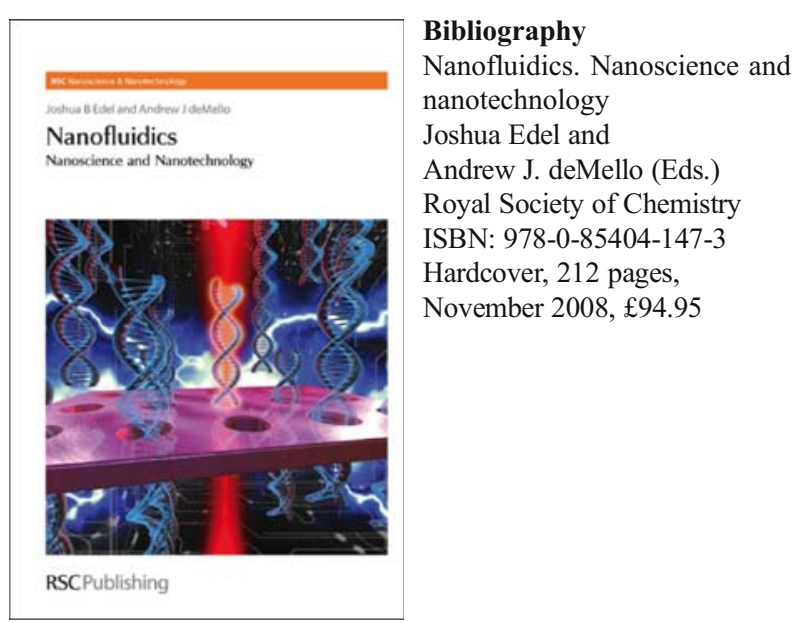

Book's topic Nanofluidics is a fairly recent discipline, which has developed within the lab-on-a-chip field of research as a logical extension of microfluidics. Nanofluidics is generally described as the study and application of fluid flow in and around structures with dimensions of $100 \mathrm{~nm}$ or smaller. This book offers a wide-ranging collection of contributions on this subject.

Contents The book is an edited compilation of nine chapters, which are written by a number of internationally acknowledged experts in this field. The research presented is for a large part fundamental, which is not surprising in view of the youthful age of this discipline.

J. Eijkel $(\bowtie)$

Twente University - EWI/BIOS,

Postbus 217, 7500 AE Enschede, The Netherlands

e-mail: j.c.t.eijkel@utwente.nl
Subjects that are treated or at least touched upon include manufacturing technologies for nanofluidic structures, fundamental transport theory of small ions and (bio) macromolecules (especially DNA) in nanofluidic channels and in nano-microfluidic constructs, molecular preconcentration and separation (again especially of DNA), singlemolecule studies in nanochannels and short nanopores, and detection (optical or electrical).

Comparison with existing literature Basically, this is the first book that is exclusively dedicated to this subject. A fair number of books already exist on microfluidics and lab on a chip that either exclusively treat theoretical aspects (e.g., Theoretical microfluidics by Henrik Bruus) or both theory and applications (e.g., Introduction to microfluidics by Patrick Tabeling). The Encyclopedia of microfluidics and nanofluidics (edited by Dongqing Li) contains a lot of nanofluidic theory but as an encyclopedia, of course, is quite costly and large.

Critical assessment This book has the typical advantages and drawbacks of edited compilations of works by different authors. An advantage is that a broad range of issues is covered in an expertly fashion. In my opinion this book contains some gems, such as the paper on ion-current rectification by Cheng and Guo that neatly combines a number of seemingly disparate systems in a single theoretical approach. Also the chapter by Kim (from the Kasianowicz group) nicely crosses boundaries by reporting on the use of both $\alpha$-hemolysin pores and inorganic nanopores for single molecule DNA studies. The drawbacks of the compilation approach are, however, that a general introduction to the field is missing, that theory is offered in a piecemeal way and sometimes in duplicate (the Poisson-Nernst-Planck 
equations, for example, are treated twice), that authors tend to report mainly on their own work, and, finally, that no unified symbols are used in the different chapters. As a result, the book reads very much like a collection of review and research papers.

Readership recommendation Because the work basically offers a number of separate review papers, it is useful for everyone interested in one or more of the subjects covered. I would hesitate to use the book for a nanofluidics course however, since the treatment is too piecemeal and insufficiently unified. Because of the breadth of the subjects covered, senior researchers, Ph.D. students, and master students in nanofluidics will often find this book very helpful.

Summary Nanofluidics, nanoscience and nanotechnology offers a wide-ranging compilation of contributions on the fundamentals and applications of nanofluidics written by expert researchers.

Open Access This article is distributed under the terms of the Creative Commons Attribution Noncommercial License which permits any noncommercial use, distribution, and reproduction in any medium, provided the original author(s) and source are credited. 